\title{
Effects of a Traditional and Web-Based Literacy Methods Class: A Study of Undergraduate Elementary Students' Performance
}

\author{
Chhanda Islam, Ph.D. \\ Professor \\ Department of Early Childhood and Elementary Education \\ 3213 Alexander Hall \\ Murray State University \\ United States
}

\begin{abstract}
This paper discusses findings of a study that examined the achievement of two distinct groups of university students who were enrolled in the same literacy methods course: one group that took the course face-to-face on campus, and a second group that took the course entirely online. The instructor, course materials, and assessments were consistent between the two delivery formats. The investigator compared student performance on a pretest and posttest exam. The results showed that there was not a 5\% significance level of difference in achievement between the overall group of online students versus the overall group of face-to-face students. There was an upward change in the mean score between the two settings, so a t-test was conducted. However, even though there was an apparent growth in knowledge, the differences between the pretest and posttest were not statistically significant. This study contributes to the research on the efficacy of online versus face-to-face learning.
\end{abstract}

Effects of a Traditional and Web-based Literacy Methods Class: A Study of Undergraduate Elementary Students' Performance

Increasingly, more instructors in higher education are teaching classes that are entirely Web-based as colleges and universities offer $100 \%$ online courses to accommodate the needs of all students and larger enrollments (Finkelstein \&Scholz, 2000). Web-based instruction has emerged as a viable alternative to traditional classroom instruction,and online enrollment has increased at a substantially faster rate than that of overall higher education (Allen \&Seaman, 2010). This online delivery of courses has become increasingly popular due to several advantages for both educational institutions and students in terms of computer technology availability, Internet access, and increases in online course offerings (Mann \& Henneberry, 2017). Even with the proliferation of online courses, universities and researchers have only just begun to investigate systematically what they can and cannot teach meritoriously online and the effectiveness of online versus face-to-face classrooms (Coughan, 2012; Gundy, Morton, Liu, \& Kline, 2006; Jaffee, 1997).

Moreover, despite the increasing popularity of online education, the broader literature on the efficacy of online courses is not conclusive. There is often a divide in the literature between studies that found face-to-face classes outperformed online courses and those that found the opposite (Allen et al., 2004; Bernard et al., 2004; Jahng, Krug, \& Zhang, 2007; Sitzmann, Kraiger, Steward, \& Wisher, 2006; Urtel, 2008). Adding to the issue is the fact that many of the studies within this body of literature relied heavily on small samples that were nonrandom, failed to replicate findings, and lacked demographic controls. Some of these studies compared courses with substantial differences in content, materials, and methods of evaluating student performance (Bernard et al., 2004; Jahng et al., 2007; Means, Toyama, Murphy, Bakia, \& Jones, 2009; Urtel, 2008).

Even though many institutions are now including online courses and programs as part of their regular course offerings, the exact manner in which the instructional model is being implemented through technology is still being investigated. A common assumption in early studies that compared online and face-to-face courses was that the levels of variation were the same across different online and face-to-face course designs (Bernard et al., 2009; Means et al., 2009). However, Bernard et al. (2009) found that online learning environments varied from one another because of the specific implementation of technological design. 
The implication was that the higher variation among online courses compared with face-to-face courses might be why some studies have found that online courses are less effective than their face-to-face counterparts (Logan, Augustyniak, \& Rees, 2002; Urtel, 2008; Winnie, 2001).Therefore, more research is needed to determine the interchangeability of online courses and face-to-face courses. Technological advances will likely continue to drive increases in online educational offerings, including online teacher preparation programs. Preservice teachers need to develop skills that will help them to be more successful in their future classrooms, which means that significant attention needs to be given to preservice teachers' ability to learn and teach via online platforms. However, few studies have examined the effects of online vs. face-to-face instructional models on preservice teachers' knowledge base. Thus, the purpose of this study was to examine the achievement of two distinct groups of university students who were enrolled in the same literacy methods course within a teacher preparation program: one group that took the course face-to-face on campus, and a second group that took the course entirely online. This study contributes to the research on the efficacy of online versus face-to-face learning.

\section{Literature Review}

Many researchers have compared the effects of learning via online course versus traditional face-to-face instruction (Sancho-Vineusa \& Gras-Marti, 2010; Tapscott, 2017; Young, Kyu, \& Eun, 2011). Empirical studies have both supported (McFarland \& Hamilton, 2005; Parkhurst et al., 2008; Russell, 1999; Summers, Waigandt, \& Whittaker, 2005; Tucker, 2001) and refuted (Logan et al., 2002; Urtel, 2008) the ability of online courses to provide a learning experience comparable to the traditional face-to-face approach irrespective of academic aptitude. Thus, debate continues about the effectiveness of online courses and whether they provide a learning experience that is equal to that of a face-to-face classroom.

\section{Online vs. Face-to-Face Instruction}

Debates about the effectiveness of online instruction are often tied to its pros and cons as a suitable medium for education. For instance, many argue that it is suitable simply due to its high demand and convenience (Logan et al., 2002; Russell, 1999; Summers et al., 2005; York, 2008). Others, however, argue that there is substantial doubt of online teaching's efficacy due to the distance it imposes between students and their instructors (Ritzer, 2004) as well as students and their peers (Parkhurst et al., 2008; Urtel, 2008).

Despite the questionable efficacy of online learning, many students now have little patience for traditional face-toface lectures and feel that an online course best fits their individual needs (Prensky, 2016). Within online courses, there are distinct opportunities for flexible, student-centered learning because students are required to take responsibility for their own education and are required to be proactive in the learning process (Logan et al., 2002). Students must self-regulate their work and assume greater accountability for online learning because instructors are not physically present to provide pace, order, and focus.

Nonetheless, although today's students tend to be adept with technology, instructors worry that online classes place too much of the burden on students and may adversely affect the learning outcomes of students. A study by Ross and Bell (2007) found that students in a face-to-face environment demonstrated a deeper level of learning, developed more abstract thinking, and showed a greater difference in test performance than those learning through strictly online asynchronous methods. Onwuegbuzie and colleagues (2007) indicated that college students often identify "the interpersonal context as the most important indicator of effective instruction" (p. 146), and of course online courses are missing that component. In addition, online courses may not always offer the best results to those students who are not self-directed (McCaslin \& Hickey, 2001). Online courses tend to rely more exclusively upon self-regulated learning, which is recognized as an important predictor of student academic motivation and achievement. Higher self-efficacy beliefs increase the use of motivation strategies and academic achievement in students. This process requires students to independently develop self-monitoring strategies. However, not all students are sufficiently proficient in self-regulating skills necessary to succeed in an online environment. Students who are not comfortable with self-regulated learning may be at a disadvantage in an online classroom (Winnie, 2001).

Additionally, the content of discussions also differs between online and face-to-face classrooms. Some studies have shown that students in face-to-face classes tend to ask far more interpretive and logistical questions during discussions, whereas online students voice more content-based questions (Logan et al., 2002). A study by Summers et al. (2005) found that these different discussions allowed students in the face-to-face classes a clearer understanding of requirements and instructions. 
The differences resulted in students of online courses developing lower cognitive development skills and lower critical thinking skills, and students felt that the instructor's explanations, concern toward students, and interest in student learning all suffered in the online environment. Although Russell's (1999) work focused on a broader range of nontraditional classroom settings than just online courses, his seminal study found that when technology is appropriately and practically applied, students can learn at their own pace. Russell's argument was that the amount of learning that occurs in a course is independent of the instructional medium or the technology involved and instead depends on the multiple instructional methods that are available in the online environment. Within the online environment, particularly within courses that are structured around an asynchronous design, effective teaching can occur where both students and teachers are invested in the learning process.

\section{Online vs. Face-to-Face Literacy Instruction}

For students in a literacy methods course, the development of appropriate knowledge, skills, and training is paramount to the emergent competency of reading instruction. High efficacy is important for students because students with higher efficacy put more effort into their work. The instructor plays an important role in students' efficacy and in improving knowledge about reading that leads to a broader and deeper understanding and preparedness for future jobs of the students and yields the most successful learning outcomes (Pressley et al., 2018).

Several studies have found that face-to-face classes have a positive influence on students' efficacy, specifically in the domain of literacy instruction (Haverback \& Parault, 2008; Rogers-Haverback \& Mee, 2015). A study by Pressley, Cartwright, and Riggins (2018) found that students in a face-to-face reading methods class, versus an asynchronous class, demonstrated broader and deeper application of knowledge and higher self-ratings of preparedness to teach literacy.

\section{A Literacy Methods Course}

A literacy methods course includes discussions on major theoretical foundations, principles, procedures, and practices that center around teaching elementary literacy — reading, writing, speaking, listening, spelling, viewing, and visual representation. Students learn how to integrate different instructional strategies, methods, and resources into curriculum. Students develop an understanding of the central concepts, tools of inquiry, and structures of the integrated readings that help them create learning experiences that are accessible and meaningful for learners (Haverback \& Parault, 2008).The course emphasizes knowledge of subject matter, research-based best practices for all learners, and reflective practice.

The course objectives are to help students learn to describe the reading process, including the cueing systems of written language; demonstrate an understanding of literacy development in children, including emergent literacy and the role of phonemic awareness; describe strategies for helping students comprehend and develop vocabulary; describe a variety of strategies for word identification (including phonics, sight words, and morphemic analysis), fluency, and motivating students to read; describe a variety of instructional approaches that are appropriate for designing literacy instruction (Rogers-Haverback \& Mee, 2015); and become familiar with the different literacy instruction in the elementary classroom that meets the needs of diverse students, including students with special learning needs and/or special language or cultural needs.

The literacy methods course that was the focus in this study was offered by a Midwestern university's Department of Early Childhood and Elementary Education. The course was available to elementary majors in a face-to-face format on campus or in a 100\% online format using the delivery system CANVAS. The instructor created modules through CANVAS that contained files, discussions, assignments, exams, and other learning materials. Within the CANVAS delivery system, YuJa virtual classroom'sauto-captioning feature enabled students to textsearch through videos to find specific areas for further review. The YuJa allowed the instructor to deliver a variety of media-rich experiences such as lecture capture, video classrooms, and social learning tools. Students and team members accessed the YuJa video lectures via CANVAS for later study or review since they were available. The instructor provided a variety of resources with an integrated cloud-based video library so students could access their learning library from virtually anywhere on any device. The instructor used YuJa's active learning platform to engage and interact with the students and to involve students in evaluating their own work, thereby promoting students' metacognition and reflection. Instructional methods in the face-to-face course were a mixture of instructor presentation, group discussion, problem solving, collaborative group work, independent readings, both group and independent assignments, and reflection. 
Students read the assigned chapters before class and prepared to take part in class-related work, writings, group work, and examinations. This course was designated as a lecture course; however, a variety of presentation methods were included, such as modeling instruction, inquiry-based guided instruction, and debriefing sessions. Students' questions and reflections upon their study were encouraged. The courses were equivalent in content and taught by the same instructor. The online and face-to-face versions of this course were purposely designed to be as similar as possible using the principles for best practices (collaboration among students, interaction between students and instructor). Some minor refinements were made based on students' needs, but the books, supplemental readings, and section topics were largely consistent throughout. During the terms in which online and face-to-face sections were being taught simultaneously, both types of classes were built around identical learning objectives and outcomes, covered the exact same content, used the same readings, and were held to identical standards in terms of level of understanding. Examinations, also the same for both classes, were designed to measure equal academic outcomes. Additionally, students taking the online literacy methods course were expected to have daily access to CANVAS and email. Using CANVAS technology, the course was structured with a row of buttons down the side. To access different parts of the course (e.g., syllabus, assignments, modules, outcomes, and YuJa virtual classroom), students were required to click on one of the buttons on the side. The course was organized on a weekly basis, meaning students had approximately a week to complete readings in the textbook and complete and post any assignments to the instructor via CANVAS.

The presentation of material in the online sections relied on a weekly PowerPoint lecture, YuJa video lectures, and asynchronous, threaded discussion boards structured around specific prompts. These discussion boards were a forum for interaction among students (students were required to comment on each other's posts) and the instructor since the instructor participated in the discussions, provided feedback on students' posts, posed further questions regarding literacy strategies, and graded the content of students' posts. Through discussion boards, students explored the relationship between reading and writing and demonstrated the use of specific strategies to implement this interrelationship; analyzed differences in literacy models of teaching and learning literacy; and selected appropriate learning experiences that enhance the development of reading, writing, listening, viewing, and speaking skills. The online sections also generated interaction between the instructor and students with regular announcements that were posted on CANVAS and sent through the CANVAS inbox/email. These announcements served to clarify misconceptions and remind students of upcoming deadlines as well as to provide broad feedback on the class performance.

\section{Methods}

The literacy methods course that was the basis for this study was offered for three credit hours and divided into two sections - one in a traditional face-to-face setting and one in an online format. The 25 undergraduate students enrolled in the face-to-face literacy methods course and the17 students who elected to take the Web-based course were selected for inclusion in this study. This was a mid-level literacy-related course that students were required to take before enrolling in their senior-level courses. The age of the enrolled students ranged from 20 to 40 years. Of the 42 students, $100 \%$ were white, $7 \%$ were male, and $93 \%$ were female.

The approach of this study was quantitative in nature. The purpose of using quantitative analysis was to measure performance through the examination of mathematical values of variables or to use evaluations in terms of a numerical value, including measurement and performance evaluation (Pyrczak \& Bruce, 2002). This study was designed as an exploratory analysis of pretest-posttest to detect if there was, in fact, significant difference in regard to students' grades in the course(Gay, 2002). The pretest-posttest design was used primarily to compare the two groups and/or measure change resulting from experimental usages. Student success in achieving the course objectives was primarily assessed through a pretest and posttest exam that consisted of a range of short answer and essay questions designed to measure how well students mastered the content and met the overall learning goals for the course. To compare online to in-class courses, the instructor relied on pretest-posttest evaluation data collected and published on CANVAS. The CANVAS evaluation systems for both types of classes were administered online, allowing all students to access their exams at any point within an approximate 24-hour window. Therefore, both the face-to-face and online sections took their exams under identical conditions.

During the period in which online and face-to-face sections were being taught simultaneously, both types of classes took the exact same exams, all of which were evaluated using the same grading rubric - a scoring tool that was used to evaluate the performance in an outcome area based on a list of criteria describing the characteristics of performances at varying levels of accomplishment. 
The criteria and performance-level descriptions in rubrics helped students understand what the desired performance should be, how they should master each criterion, or what their next steps should be to enhance the quality of their performance.

The research analysis focused on the following question: Was there any difference in knowledge as measured by student scores on the examinations? Although the pretest and posttest evaluations were certainly limited instruments for capturing how well students were meeting all the learning objectives for the course, they provided a solid indication of how successfully students were learning. The pretest and posttest for the online class and the face to-face class were exactly the same, totaled 100 items, and tested students' knowledge in researchbased classroom strategies to help build and strengthen literacy skills in phonics, fluency, print awareness, phonological awareness, vocabulary, comprehension, and writing. By using questions that required students to apply course concepts, the instructor was able to directly measure the course goal. The essay questions were particularly designed to evaluate students' higher-level learning and to assess students' understanding of and ability to think with subject matter content. By structuring essay questions around different research-based literacy strategies, literacy practices to support effective teaching, and different theories, the instructor was able to analyze how well students were meeting the learning outcomes. Short-answer questions were openended questions that required students to fully explore the key concepts or ideas related to literacy theories that have developed over the last decades from in-depth scientific and social research. Students were asked to highlight different theoretical perspectives on the learning of literacy and their actual practice in classroom. Topics explored included, for example, how children develop multidimensional abilities such as listening, speaking, viewing, and performing and how cultural and societal factors facilitate or constrain their literacy development. Short-answer questions were used to get more calibrated results by assessing students' understanding of course content and their level of competency in applying what they were learning.

\section{Results}

The purpose of this study was to examine the achievement of two different groups of university students who were enrolled in the same literacy methods course: one group that took the course face-to-face on campus, and a second group that took the course entirely online. Students' knowledge was measured by establishing a cumulative score for students based on the sum of their performance on a pretest and posttest exam. The data used were obtained from the instructor's records of students' grades on course pretest and posttest assessments. To measure students' knowledge in course content, open-ended questions were used. The data were created by analyzing the data between groups. The results showed that on the pretest, $91 \%$ of face-to-face and $90 \%$ of online students thoroughly discussed strategies for teaching comprehension, including a literacy continuum for the primary grades; teaching ideas that focused on phonemic awareness; and phonics, fluency, vocabulary, and writing.

Both face-to-face and online students discussed the effectiveness of literacy strategies as tools for enhancing the reading achievement of different learner types, particularly low-achieving students, representing the range of academic diversity typically present in primary grade classrooms. In addition, both groups discussed the developmental theories associated with language, literacy, and cognition and the nature of language and literacy instruction.

In addition, on the posttest, $95 \%$ of face-to-face students and $93 \%$ of online students perceived the importance of teaching reading and writing as interrelated processes and discussed the role and value of oral language in the processes of reading, writing, viewing, listening, and performing. Both face-to-face and online students explained the role and value of planning, delivering, and evaluating instruction based upon an understanding of theories, processes, and characteristics of learners, teaching methods, and resources in the learning environment. Also on the posttest, both groups explained the conditions and experiences that contribute to and support growth in reading and writing. Both groups further elaborated on literacy strategies and when to use them to contribute to the learner's reading and writing growth, and both explained in detail the characteristics of texts, the learning environment, and readers' sociolinguistic background that can affect the strategies readers use to derive meaning from text. Finally, both groups discussed how to design, select, modify, and evaluate materials that reflect curriculum goals, current knowledge, and the interests, motivation, and needs of individual learners. 
Both face-to-face students and online students scored higher on their posttest than they did on their pretest. Specifically, $4 \%$ of face-to-face students and 3\% of online students posted higher scores on their posttest than they did on their pretest. Therefore, both the online and face-to-face classes had percentages for increased test scores, thereby allowing the instructor to categorize the likely test performance of face-to-face and online students into higher- and lower-performing groups. The analysis of the results showed that the test sub-groups of lowerperforming students in the online class compared to the face-to-face group were not significantly different in their academic aptitude; similarly, for the higher-performing students, the online and the face-to-face higherperforming students were not significantly different in their academic aptitude. This finding was consistent with previous research wherein students were evaluated on their knowledge base by using their cumulative test scores from the class, and no significant differences on academic knowledge were found between the groups at the end of the course (Raine et al., 2011). The results provided support for some of the past conclusions from both Russell's (1999) study(no significant difference) and Ross and Bell's (2007)study (cognitive skill level difference).

The high-performing students in both groups completed answers with sufficient detail; provided examples to support assertions; focused on issues related to the question; showed their understanding of the issues; and presented a strong and insightful thesis or point of view. Their answers showed originality, elegance, synthesis of ideas, and clear thinking. In contrast, the low-performing students in both groups presented only an adequate response to the topic (demonstrating superficial analysis and weak point of view). They used logical reasoning, but the supporting evidence was general and imprecise with few examples. They offered simplistic, undeveloped, or cryptic support for the ideas, inappropriate or off-topic generalizations, and faulty assumptions based on incoherent facts. Most importantly, though, the results showed that none of the overall groups of online versus face-to-face students reached a 5\% significance level.

After determining there was no significant difference between the two groups, the data between the groups were calculated. The face-to-face mean for the pretest was 0.66, while the online pretest mean was 0.63 (Figure 1). Even though there was a difference, the difference was not statistically significant. In addition, in terms of the posttest scores, even though there was a difference in the mean, with a face-to-face of 0.73 versus an online of 0.70 , the difference was also not significant (Figure 2). There was an upward change in the mean score, so a t-test was conducted. However, even though there was an apparent growth in knowledge, the differences between the pretest and posttest were not statistically significant.

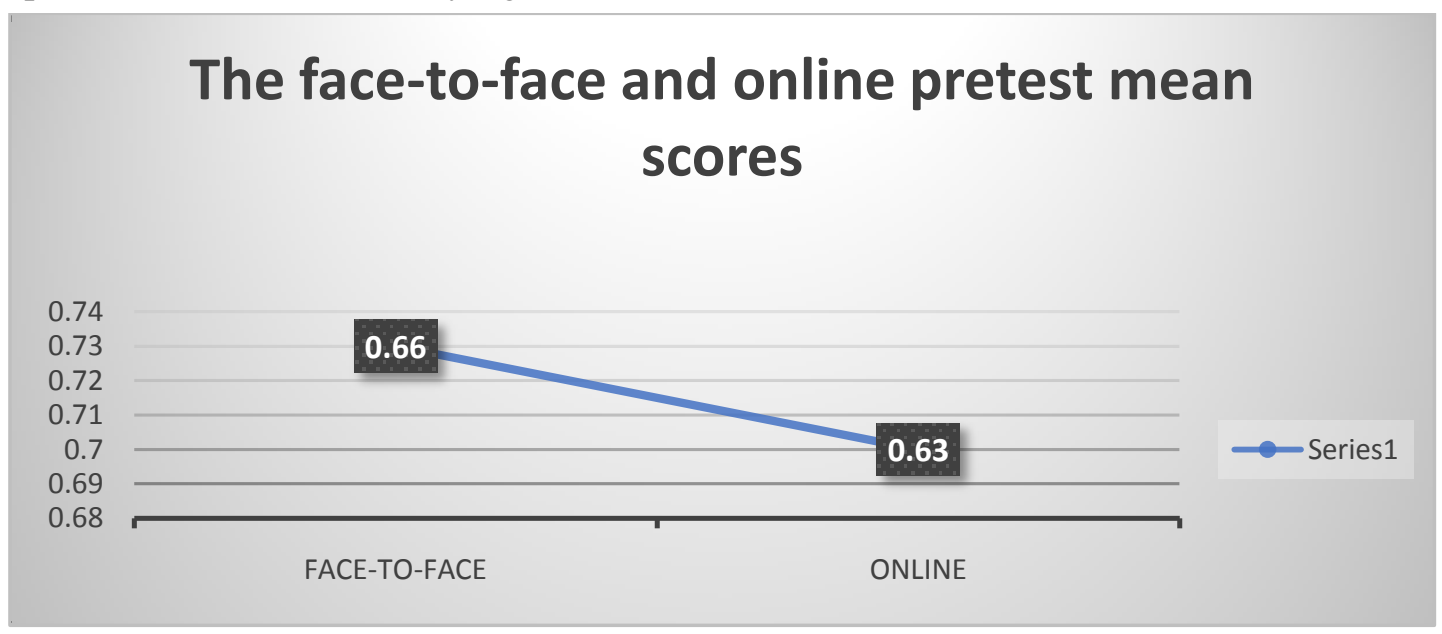

Figure 1. Pretest mean scores for face-to-face and online students. 


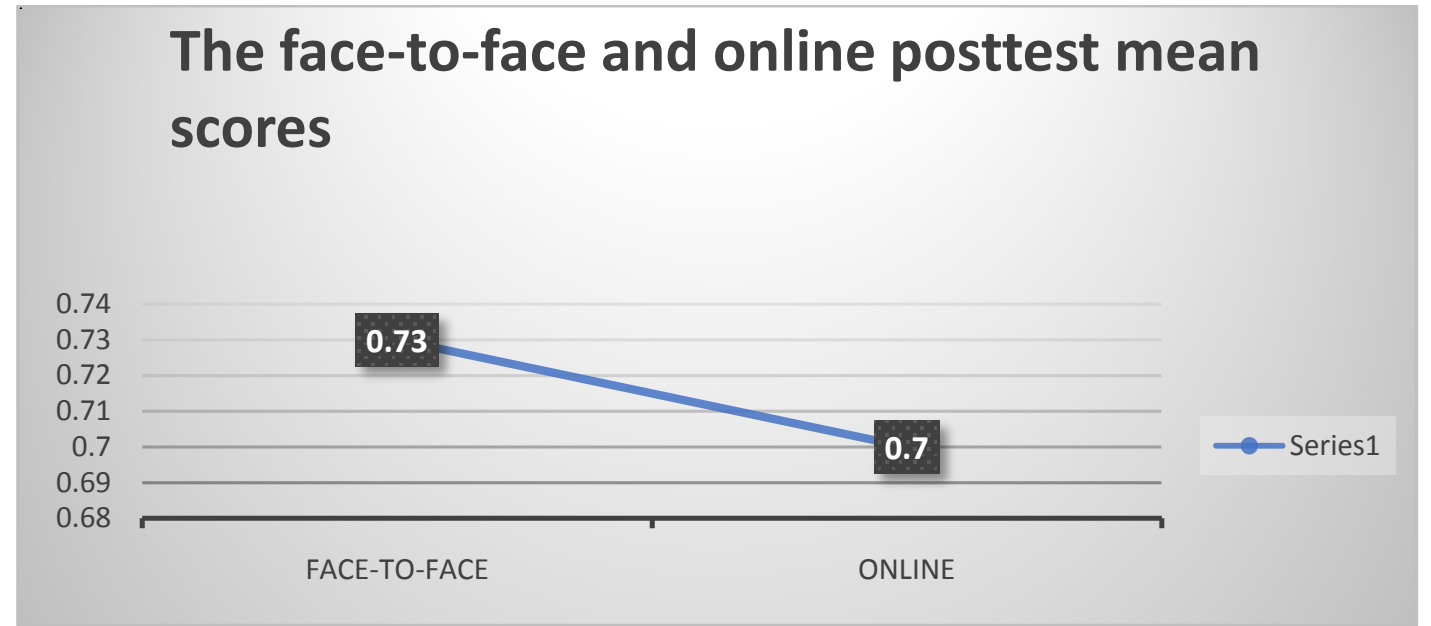

Figure 2. Posttest mean scores for face-to-face and online students.

\section{Conclusion and Recommendations for Future Research}

This study was designed to assess differences in student performance between students in an online classroom and students in a traditional face-to-face classroom. Data were collected from students enrolled in both an online and face-to-face section of a literacy methods course. The instructor, course materials, and assessments were consistent between the two delivery formats. The investigator compared student performance on a pretest and posttest exam. Mean comparisons of both groups showed that students in the face-to-face sections of the course performed better on both assessments than students in the online sections. However, no significant differences emerged. Based on the results, it was postulated that academically stronger students might be gravitating toward the face-to-face sections of the course, creating a corresponding difference in student performance between the two types of classes. The face-to-face environment provided students with the opportunity to bring up questions for clarification and elaboration on topics at the moment of the presentation of a topic. Face-to-face students received clarification immediately during the lecture for topics that required a great deal of abstract thinking, which helped them avoid confusion. In the face-to-face class, difficult concepts were explored interactively with direct interaction between the instructor and the student. In a recorded lecture scenario, that interactive and synchronized approach was lost. Most likely, online students had a challenging time understanding a concept through viewing a recorded lecture and thus failed to achieve the deeper level of learning needed to answer a complex question. One potential explanation was that academically weaker students were more reliant upon their instructor and required a higher degree of mentoring. These types of students tend to struggle academically or possess a lower ability to learn independently (Summers et al., 2005).

The results highlighted the need for further examination of which students are electing to take online classes and the reasons behind that decision. Future research should examine the motivations behind students' preferences for different learning environments. From a practical standpoint, an open-ended questionnaire concerning the selection of online, hybrid (a combination of face-to-face and online sessions), or face-to-face course sections would aid in understanding the factors of student choice. Furthermore, because of the possibility that the increased number of high-performing students in the face-to-face section of the course was determined by the specific policies of the university where the study was conducted, there is a need to conduct similar studies at other universities with different policies. Results may be different for different regions of the state and nation and may be influenced by different types of university policies. Finally, the instructor should take advantage of the best features of both face-to-face and online learning and consider designing more hybrid courses that encourage a student-centered approach to learning.

\section{Limitations}

The generalizability of the results of this study is limited due to the small number of participants. A study with a larger sample would allow for more valid conclusions. A similar study extended over a longer period would allow more participants and generate a different configuration of students. Moreover, it was accepted that the pretest and posttest were designed to ensure that the class obtained the knowledge necessary to successfully meet the course objectives. A different set of tests and format combined with course assignments should be used for more consistent outcomes in comparing the coursework with different settings (Raine et al., 2011). 
Finally, it was assumed that all the students in the online class were comfortable with the online format, were computer literate, and had adequate Internet connections. Questions concerning the technology itself were not posed in this study. This variable could have hampered student performance in the course as well. As universities offer more online and hybrid courses, future research should examine students' technology proficiency and its relationship to student achievement.

\section{References}

Allen, I. E., \& Seaman, J. (2010). Class differences: Online education in the United States, 2010. Retrieved from the Sloan Consortium website: http://sloanconsortium.org/publication ns/survey/class_differences

Allen, M., Mabry, E., Mattrey, M., Bourhis, J., Titsworth, S., \& Burrell, N. (2004). Evaluating the effectiveness of distance learning: A comparison using meta-analysis. International Communication Association,54(3), 402-420.

Bernard, R. M., Abrami, P. C.,Evgueni, Y. L., Wade, A., Wozney, L., Andrew, P. W., . . Huang, B. (2004). How does distance education compare to classroom instruction? A meta-analysis of empirical literature. Review of Educational Research,74(3), 379-439.

Coughan, S. (2012). MIT launches free online "fully automated" course. BBC News. Retrieved from http://www.bbc.co.uk/news/education-17012968

Finkelstein, M. J.,\& Scholz, W. B. (2000). What do we know about information technology and the cost of collegiate teaching and learning? In M. J. Finkelstein, C. Frances, F. I. Jewett, \&B. W. Scholz (Eds.),Dollars, distance, and online education: The new economics of college teaching and learning(pp. 3-34). Phoenix, AZ: Oryx Press.

Gay, R. L. (2002). Educational research: Competencies for analysis and application. Kent, OH: Prentice Hall.

Gundy, K. V., Morton, B. A., Liu, H. Q., \& Kline, J. (2006). Effects of web-based instruction on math anxiety, the sense of mastery, and global self-esteem: A quasi-experimental study of undergraduate statistics students. Teaching Sociology, 34(4), 370-388.

Haverback, H. R.,\& Parault, S. T. (2008). Preservice reading teacher efficacy and tutoring: A review. Educational Psychology Review, 20(3), 237-255.

Jaffee, D. (1997). Asynchronous learning: Technology and pedagogical strategy in a distance learning course. Teaching Sociology,25(4), 262-277.

Jahng, N., Krug, D., \& Zhang, Z. (2007). Student achievement in online distance education compared to face-toface education. European Journal of Open, Distance, and E-Learning. Retrieved from http://www.eurodl.org/materials/contrib/2007/Jahng_Krug_Zhang.htm

Logan, E., Augustyniak, R.,\& Rees, A. (2002). Distance education as different education: Astudent-centered investigation of distance learning experience. Journal of Education for Library and Information Science,43(1), 32-42.

Mann, T. J.,\& Henneberry, R. S. (2017). Online versus face-to-face: Students' preferences for college courses attributes. Literacy Practice and Research, 42(2), 6-34.

McCaslin, M., \& Hickey, D. (2001). Self-regulated learning and academic achievement: A Vygotskian view. In B. J. Zimmerman \& D. H. Schunk (Eds.), Self-regulated learning and academic achievement: Theoretical perspectives (pp. 227-252). Mahwah, NJ: Lawrence Erlbaum.

McFarland, D.,\& Hamilton, D. (2005). Factors affecting student performance and satisfaction: Online versus traditional course delivery. Journal of Computer Information Systems,46(2), 25-32.

Means, B., Toyama, Y., Murphy, R., Bakia, M., \& Jones, K. (2009). Evaluation of evidence-based practices in online learning: A meta-analysis and review of online learning studies. Retrieved from U.S. Department of Education website: https://www2.ed.gov/rschstat/eval/tech/evidence-based-practices/finalreport.pdf

Onwuegbuzie, A. J., Witcher, E. A., Collins, K., Filer, D. J., Wiedmaier, D. C., \& Moore, W. C. (2007). Students' perceptions of characteristics of effective college teachers: A validity study of a teaching evaluation form using a mixed-methods analysis. American Educational Research Journal, 44(1), 11-12.

Parkhurst, R., Moskal, B., Downey, L. G., Lucena, J., Bigley, T., \& Elberb, S. (2008). Engineering cultures: Comparing student learning in online and classroom based implementations. International Journal of Engineering Education, 24(5), 955-964.

Prensky, M. (2016). Listen to the natives. Educational Leadership, 63(4), 8-13. 
Pressley, T., Cartwright, K. B.,\& Riggins, C. E. (2018). Effects of synchronous versus asynchronous scheduling of reading methods content and field instruction on pre-service teachers' efficacy and knowledge. Literacy Practice and Research, 43(2), 5-13.

Pyrczak, F.,\& Bruce, R. R. (2002). Writing empirical research reports. Glendale, CA: Pyrczak.

Raine, L., Reid, M., Styker, A., Clark, R., Frias, L., \& Szabo, S. (2011). Online class versus face-to-face class: How do undergraduate education students perform? Literacy Promises, Association of Literacy Educators and Researchers Yearbook, 33, 153-166.

Ritzer, G. (2004). The McDonaldization of society (4th ed.). Thousand Oaks, CA: Pine Forge Press.

Rogers-Haverback, H.,\& Mee, M. (2015). Reading and teaching in an urban middle school: Preservice teachers' self-efficacy beliefs and field-based experiences. Middle Grades Research Journal, 10(1), 17-30.

Ross, T. K., \& Bell, P. D. (2007). No significant difference only on the surface. International Journal of Instructional Technology and Distance Learning,4(7), 3-13.

Russell, T. L. (1999). The no significant difference phenomenon. Raleigh, NC: Office of Instructional Telecommunications, North Carolina State University.

Sancho-Vineusa, T., \&Gras-Marti, A. (2010). Teaching and learning undergraduate mathematics in an online university. In W. Kinuthia \& S. Marshall (Eds.), Educational technology in practice: Research and practical case studies from the field (pp. 145-152). New York, NY: Information Age.

Sitzmann, T., Kraiger, K., Steward, D.,\& Wisher, R. (2006). The comparative effectiveness of web-based and classroom instruction: A meta-analysis. Personnel Psychology,59(3), 623-664.

Summers, J., Waigandt, A., \& Whittaker, A. T. (2005). A comparison of student achievement and satisfaction in an online versus a traditional face-to-face statistics class. Innovative Higher Education,29(3), 233-250.

Tapscott, D. (2017). Grown up digital: How the net generation is changing your world. New York, NY: McGraw-Hill.

Tucker, S. (2001). Distance education: Better, worse, or as good as traditional education? Journal of Distance Learning Administration, 4(4). Retrieved from http://www.westga.edu/ distance/ojdla/winter44/tucker44.html

Urtel, M. G. (2008). Assessing academic performance between traditional and distance education course formats. Educational Technology \& Society, 11(1), 322-330.

Winne, P. (2001). Self-regulated learning viewed from models of information processing. In B.J. Zimmerman \& D. H. Schunk (Eds.), Self-regulated learning and academic achievement: Theoretical perspectives (pp. 153-190). Mahwah, NJ: Lawrence Erlbaum.

York, R. O. (2008). Comparing three modes instruction in a graduate social work program. Journal of Social Work Education,44(2), 157-171.

Young, J., Kyu, Y., \& Eun, K. (2011). Online university students' satisfaction and persistence: Examining perceived level of presence, usefulness and ease of use as predictors in a structural model. Computers and Education, 57, 1665-1674. doi:10.1016/j.compedu.2011.02.008 